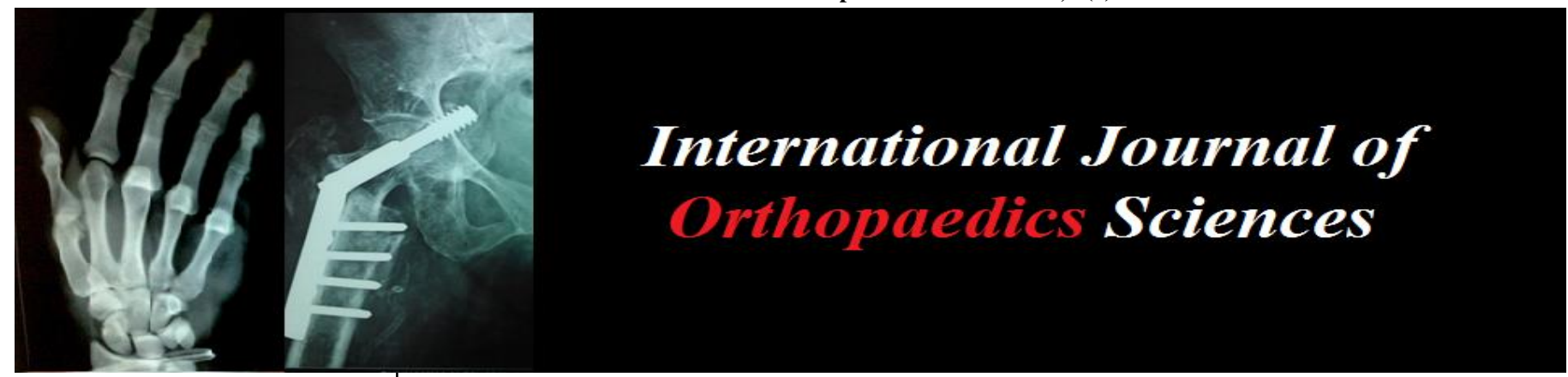

E-ISSN: 2395-1958

P-ISSN: 2706-6630

IJOS 2020; 6(3): 341-345

(C) 2020 IJOS

www.orthopaper.com

Received: 08-05-2020

Accepted: 12-06-2020

Vipin Singh

Resident, Department of

Orthopaedics GMC \& Hamidia

Hospital Bhopal, Madhya

Pradesh, India

Santosh Mishra

Assistant Professor, Department of Orthopaedics GMC \& Hamidia

Hospital Bhopal, Madhya

Pradesh, India

\section{Harendra Singh}

Resident, Department of Orthopaedics, GMC \& Hamidia

Hospital Bhopal, Madhya

Pradesh, India

Tapan Jain

Resident, Department of

Orthopaedics, GMC \& Hamidia

Hospital Bhopal, Madhya

Pradesh, India

\section{Anil Chouksey}

Resident, Department of

Orthopaedics, GMC \& Hamidia

Hospital Bhopal, Madhya

Pradesh, India

Lakshya Bharadwaj

Resident, Department of

Orthopaedics, GMC \& Hamidia

Hospital Bhopal, Madhya

Pradesh, India

\section{Suneet Tandon}

Professor, Department of

Orthopaedics, GMC \& Hamidia

Hospital Bhopal, Madhya

Pradesh, India
Corresponding Author:

Santosh Mishra

Assistant Professor, Department of Orthopaedics GMC \& Hamidia Hospital Bhopal, Madhya

Pradesh, India

\section{CT aided morphometric measurements of various pedicle parameters in different age groups of Indian population}

\author{
Vipin Singh, Santosh Mishra, Harendra Singh, Tapan Jain, Anil \\ Chouksey, Lakshya Bharadwaj and Suneet Tandon
}

DOI: $\underline{\text { https://doi.org/10.22271/ortho.2020.v6.i3f.2220 }}$

\section{Abstract}

The main objective of our study was to quantify the trends in various morphometric parameters of the pedicles of the Indian population in different age groups. A total of 200 patients between 20-70 years age underwent standard thoraco-lumbar CT scan. The patients were grouped according to age: group 1 (2030 years), group 2 (31-40years), group 3 (41-50years), group 4 (51-60 years) and group 5(61-70 years). Morphometric characteristics of transverse pedicle isthmus width, pedicle length \& transverse pedicle angle from D6-L5 vertebrae were studied. Transverse pedicle isthmus width progressively increased from T6-T12, L1-L5 in both males and females. Maximum width being at S1 (mean 19.26mm) and minimum at T6 (mean $4.2 \mathrm{~mm}$ ). Pedicle width in thoracic vertebrae were slightly higher in older age groups while in lumbar vertebrae values were higher in younger age groups. Pedicle length gradually increased from T6-T12 $(10.79 \mathrm{~mm}-15.35 \mathrm{~mm})$ vertebrae while in lumbar vertebrae longest pedicle was found at L2 $(14.08 \mathrm{~mm})$ and smallest at $\mathrm{L} 5(12.04 \mathrm{~mm})$. With increasing age, angle of vertebral entry point also increased except being constant at some vertebral level.

Keywords: Morphometry, pedicle length, transverse pedicle angle, transverse pedicle isthmus width, pedicle screw, transpedicular screw fixation

\section{Introduction}

Vertebrae is the set of 33 individual and interlocking bones which forms the spinal column. Each vertebra has three main functional components i.e. vertebral body for load-bearing, vertebral arch to protect the spinal cord and the transverse developments for ligament attachment. Vertebrae are interlocked by facet joints which allows the flexibility in the spine. Thoracic portion of vertebral column is very complex with two end segments seeming to be transitional zones towards cervical i.e. T1 to T3 and lumbar i.e. T9-T12 region. The middle part is most important because of the presence of the combination of narrow spinal canal and critical vascular supply ${ }^{[1]}$.

The thoracolumbar region of spine is the area of transfer of bio-mechanical movement in the spine, therefore, it is the area where pathologies are seen most often. These pathologies may include trauma(two main types are fractures and dislocations), degenerative diseases, osteoporotic compression fractures, instabilities, neoplastic diseases, and infections. The instrumentation of the thoracolumbar region with transpedicular screws is the most current and widespread choice in the treatment of these diseases ${ }^{[2]}$.

Vertebral pedicles are small, thick curved dorsal projections from the superior part of the body at the confluence of its lateral and dorsal surfaces ${ }^{[3]}$. The load in thoracic and lumbar region is transmitted through two vertical running columns, anterior of which is formed by vertebral bodies and inter vertebral discs while posterior column is formed by successive articulation of neural arch element (facet joints, laminae, and ligament complex) ${ }^{[4]}$. Pedicle act as a strut to transmit forces between the body and neural arch ${ }^{[5]}$. Morphometric characteristics of the pedicle should be obtained at the level of the "pedicle isthmus", which is defined as the narrowest portion of the pedicle, and therefore its dimensions represent the minimum diameter that the screw must have for adequate pedicle fixation ${ }^{[6]}$. 
As regards to the morphometrical data it is well established that same varies with different age, sex, race, ethnic \& regional group. Even though transpedicular screw fixation is performed widely over the globe, we see little studies being done on the morphometry of pedicles in Indian context. Hence there is need of our own morphometrical data specifically relevant to this region which if found appropriate will fill up the big void ${ }^{[7]}$. This data generated will be relevant and will help surgeons dealing with pedicle screw fixation.

Current observation study is to measure the surgically relevant parameters of transverse pedicle isthmus width, transverse pedicle angle and the pedicle length from D6-L5 Vertebrae in various age groups so that it can be emphasized that what changes take place with the increasing age.
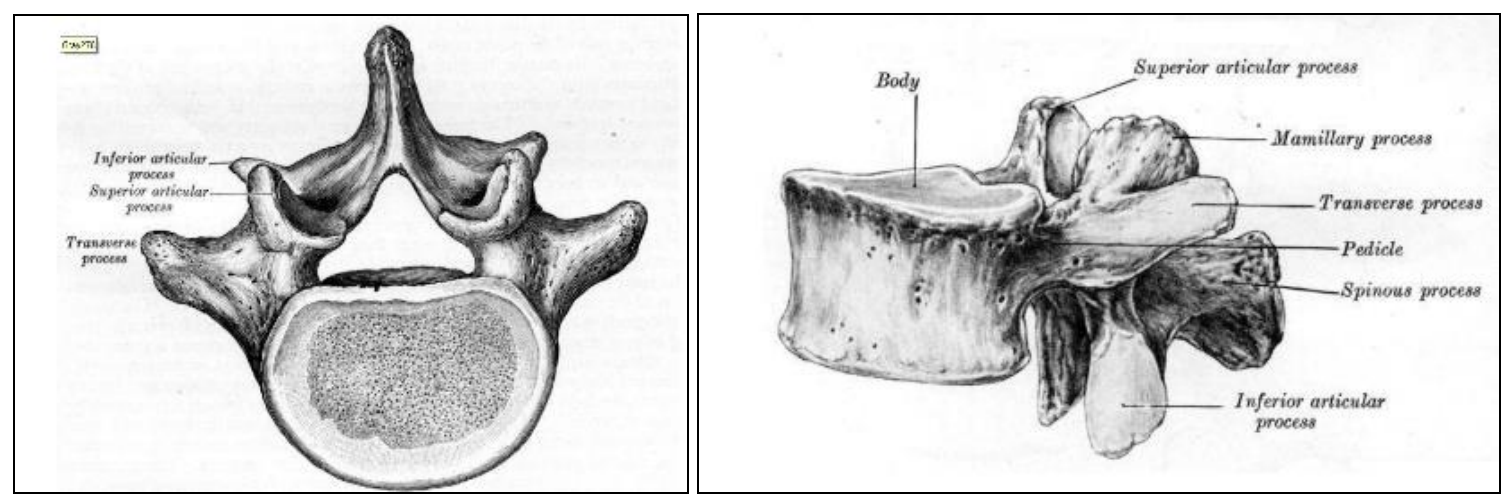

Fig 1: Anatomy

\section{Surgical landmarks to the pedicle}

Straight ahead by Roy- Camille, Inward by Magrel, Up and In by Levine and Edwards. Many proponents of the pedicle screw systems have studied the entry point for pedicular centre. The most widely used are.

a. Roy Camille [8]: The pedicle centre lies at the intersection of vertical line through the facet joint and horizontal line through the middle of the transverse process.

b. Weinstein ${ }^{[9]}$ : At the lateral and inferior corner of the superior articular facet.

c. Steffee ${ }^{[10]}$ : Recommended entry point at what he called as the "force nucleus" of the vertebra. It lies at the convergence of the ridge on the superior articular facet, the ridge on the pars interarticularis and the ridge on the transverse process.

d. Zindrik ${ }^{[11]}$ : Described a "pedicle approach zone". This is a funnel shaped area, which should be a decorticated before entering the pedicle.

\section{Materials and Methods}

This prospective \& observational study was conducted from January 2018 to August 2019. A total of 200 patients who were going to be treated with spinal pedicle screw fixation from D6- L5 vertebral level and aged between more than 20 years to less than 70 years were included in the study. All the patients with grave prognosis and non-consenting, known cases of previous spinal surgeries, growth disorders, systemic bone disease, renal disease and malabsorption syndrome, individual vertebrae with congenital anomalies and metastasis and patients aged less than $10 \mathrm{yrs}$. and more than $70 \mathrm{yrs}$ were excluded from the study.

After taking informed consent CT scan images of dorsolumbar spine were obtained. 3mm cut sections or "slices" were taken in the transverse plane which provides all the parameters of study. The distances and angles were measured by lines drawn on the CT scan images using option provided in the DICOM software and the values were directly noted from the monitor screen.

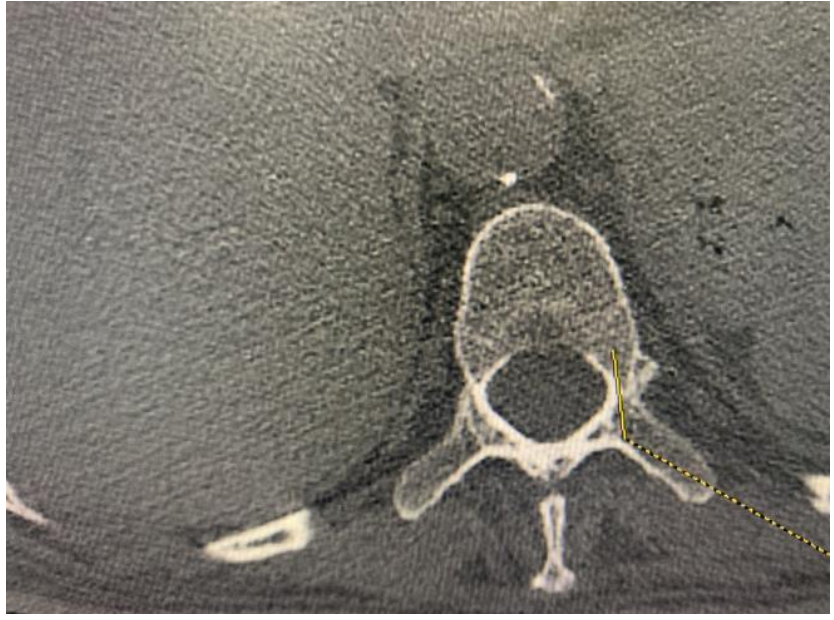

Fig 2: Pedicle Length (PL): Distance from the posterior cortex of pedicle to the junction of pedicle with vertebral body in line with the axis of pedicle.

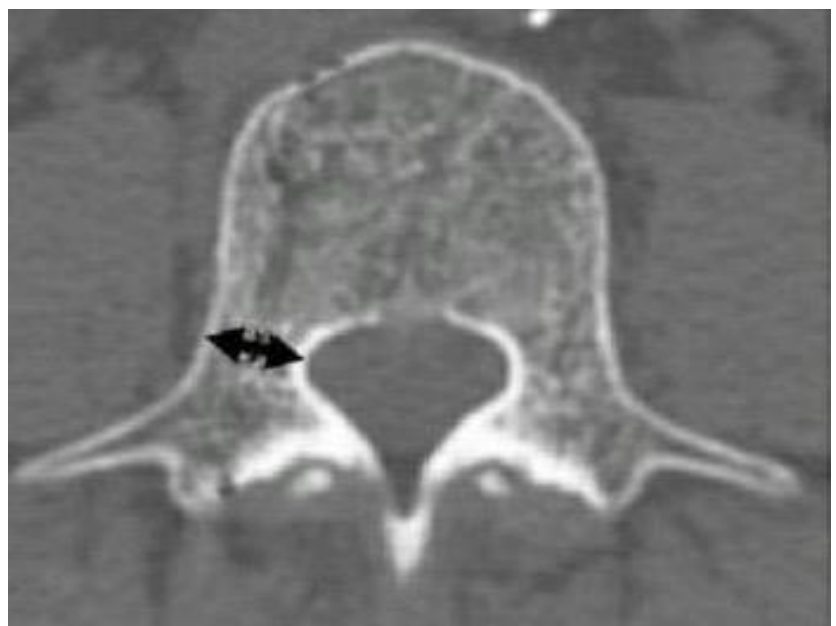

Fig 3: Transverse Pedicle Isthmus Width (TPIW): As the transverse diameter of the pedicle perpendicular to the long axis of the pedicle, at the level of least value for the width (i.e., at the level of isthmus) 


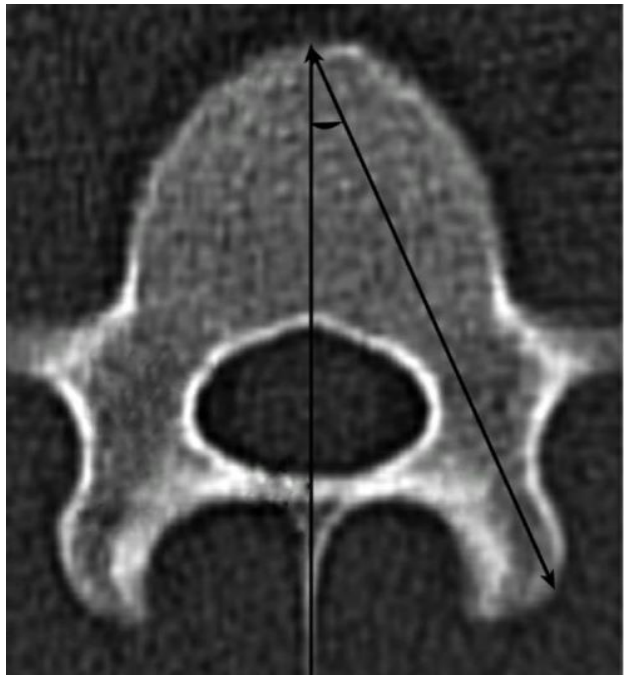

Fig 4: Transverse Pedicle Angle: The angle formed by the long axis of pedicle with that of the median transverse plane

\section{Results}

The Pedicle length, Transverse pedicle isthmus width, Transverse pedicle angle of dorso-lumbar spine were measured using the CT Scan images and the results were compared between different age groups. Mean age of patients participating in the study was 47 years. Our study included $112(56 \%)$ male and 88 (44\%) female patients. Maximum patients were distributed in $40-50$ years age group being $30 \%$ of study population.
Table 1: Distribution of patients on the basis of Age

\begin{tabular}{|c|c|c|}
\hline Age group & Frequency & Percent $(\boldsymbol{\%})$ \\
\hline 20-30 years & 30 & 15 \\
\hline 30-40 years & 40 & 20 \\
\hline 40-50 years & 60 & 30 \\
\hline 50-60 years & 50 & 25 \\
\hline 60-70 years & 20 & 10 \\
\hline
\end{tabular}

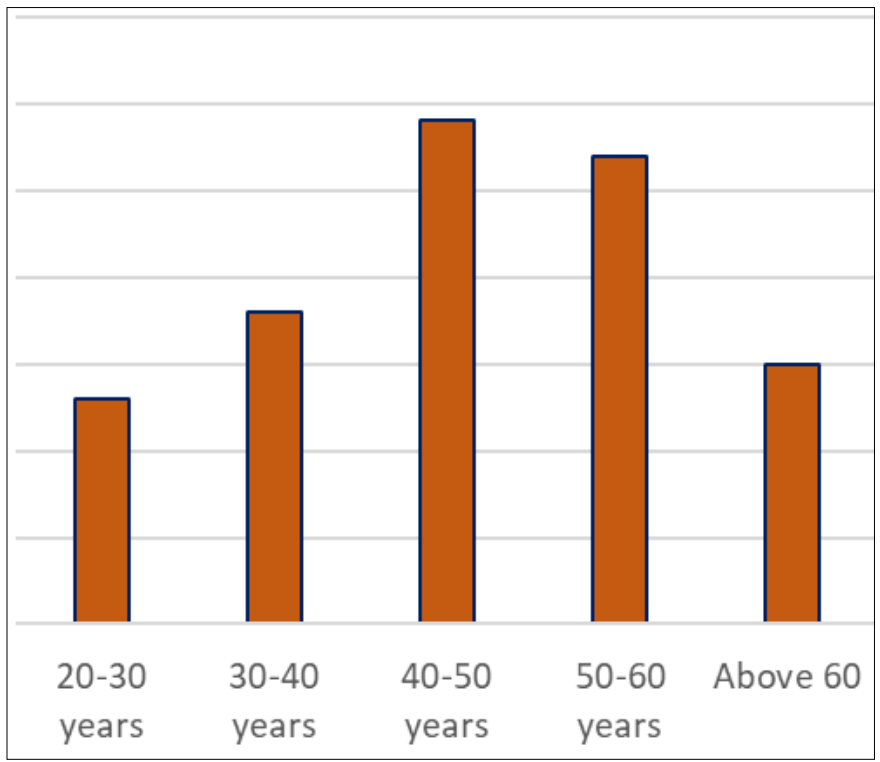

Fig 5: Graph showing distribution

Table 2: Age-wise distribution of patient's mean score of Transverse pedicle isthmus width (mm) TPIW

\begin{tabular}{|c|c|c|c|c|c|c|c|c|c|c|}
\hline & \multicolumn{10}{|c|}{ Transverse pedicle isthmus width (mm) } \\
\hline & \multicolumn{10}{|c|}{ Age (years) } \\
\hline & \multicolumn{2}{|c|}{$20-30$} & \multicolumn{2}{|c|}{$30-40$} & \multicolumn{2}{|c|}{$40-50$} & \multicolumn{2}{|c|}{$50-60$} & \multicolumn{2}{|c|}{ Above 60} \\
\hline & Mean & SD & Mean & SD & Mean & SD & Mean & SD & Mean & S D \\
\hline T6 & 4.10 & 1.38 & 4.01 & 1.03 & 3.91 & 1.11 & 4.32 & 1.10 & 4.74 & 1.27 \\
\hline T7 & 4.52 & 1.05 & 4.49 & 1.09 & 4.50 & 1.02 & 4.23 & 1.04 & 4.78 & 1.32 \\
\hline $\mathrm{T} 8$ & 4.97 & 1.06 & 4.39 & 1.01 & 4.34 & 1.04 & 4.65 & 1.21 & 4.08 & 1.14 \\
\hline T9 & 5.29 & 1.07 & 5.38 & 1.46 & 4.95 & 1.32 & 5.35 & 1.47 & 5.21 & 1.19 \\
\hline $\mathrm{T} 10$ & 5.77 & 0.81 & 6.45 & 1.51 & 6.02 & 1.02 & 6.60 & 1.00 & 5.99 & 1.05 \\
\hline $\mathrm{T} 11$ & 6.58 & 1.16 & 6.20 & 1.26 & 6.58 & 1.44 & 6.24 & 1.32 & 6.73 & 0.99 \\
\hline T12 & 7.54 & 1.19 & 7.15 & 1.13 & 7.69 & 1.08 & 7.32 & 1.09 & 7.62 & 1.22 \\
\hline L1 & 6.77 & 1.10 & 6.44 & 1.25 & 7.13 & 1.10 & 6.47 & 1.08 & 6.62 & 0.81 \\
\hline L2 & 7.16 & 1.73 & 7.98 & 1.29 & 6.83 & 1.19 & 6.84 & 1.24 & 7.51 & 1.37 \\
\hline L3 & 9.10 & 1.51 & 8.19 & 1.96 & 8.49 & 1.82 & 8.24 & 1.79 & 8.10 & 1.61 \\
\hline L4 & 10.48 & 2.60 & 10.53 & 2.84 & 10.73 & 2.48 & 11.21 & 2.81 & 11.15 & 2.56 \\
\hline L5 & 13.42 & 2.90 & 14.46 & 2.86 & 13.95 & 2.78 & 13.62 & 3.73 & 13.96 & 1.72 \\
\hline
\end{tabular}

Table 3: Age-wise distribution of patient's mean score of Pedicle length (mm)

\begin{tabular}{|c|c|c|c|c|c|c|c|c|c|c|}
\hline & \multicolumn{9}{|c|}{ 20-30 } & \multicolumn{2}{c|}{$\mathbf{3 0 - 4 0}$} & \multicolumn{2}{c|}{ 40-50 } & \multicolumn{2}{|c|}{$\mathbf{5 0 - 6 0}$} & \multicolumn{2}{c|}{ Above 60 } \\
\cline { 2 - 11 } & Mean & SD & Mean & SD & Mean & SD & Mean & SD & Mean & SD \\
\cline { 2 - 11 } & 9.62 & 2.28 & 11.48 & 3.58 & 9.72 & 2.63 & 11.70 & 3.10 & 11.25 & 2.79 \\
\hline T6 & 10.14 & 2.14 & 9.98 & 1.94 & 10.69 & 2.07 & 11.51 & 2.11 & 10.67 & 2.81 \\
\hline T7 & 10.05 & 2.26 & 11.31 & 1.34 & 10.77 & 1.78 & 11.12 & 2.08 & 10.91 & 2.69 \\
\hline T8 & 11.59 & 2.93 & 12.46 & 2.79 & 12.51 & 3.25 & 12.59 & 2.94 & 12.24 & 2.96 \\
\hline T9 & 12.55 & 2.84 & 14.67 & 3.02 & 14.44 & 2.54 & 13.23 & 2.78 & 12.64 & 3.25 \\
\hline T10 & 15.06 & 2.86 & 13.75 & 2.71 & 14.55 & 2.70 & 15.09 & 2.71 & 14.94 & 2.91 \\
\hline T11 & 14.78 & 2.61 & 15.62 & 2.83 & 15.47 & 2.67 & 14.53 & 1.97 & 14.44 & 3.39 \\
\hline T12 & 12.17 & 1.61 & 14.16 & 2.36 & 13.57 & 1.88 & 13.11 & 1.72 & 13.74 & 2.22 \\
\hline L1 & 13.05 & 2.33 & 14.17 & 1.85 & 13.95 & 1.97 & 14.47 & 1.82 & 14.27 & 3.27 \\
\hline L2 & 14.42 & 2.17 & 13.64 & 2.00 & 13.65 & 1.75 & 13.73 & 1.32 & 12.71 & 2.29 \\
\hline L3 & 11.49 & 2.48 & 12.45 & 1.99 & 12.11 & 2.19 & 12.90 & 2.62 & 12.35 & 2.22 \\
\hline L4 & 12.69 & 2.69 & 12.60 & 2.50 & 11.97 & 2.22 & 11.62 & 2.00 & 11.76 & 2.25 \\
\hline L5 & 12.69 \\
\hline
\end{tabular}


Table 4: Age-wise distribution of patient's mean score of transverse pedicle angle

\begin{tabular}{|c|c|c|c|c|c|c|c|c|c|c|}
\hline & \multicolumn{9}{|c|}{ Age (years) } \\
\cline { 2 - 12 } & \multicolumn{2}{|c|}{$\mathbf{2 0 - 3 0}$} & \multicolumn{2}{c|}{$\mathbf{3 0 - 4 0}$} & \multicolumn{2}{|c|}{ 40-50 } & \multicolumn{2}{c|}{$\mathbf{5 0 - 6 0}$} & \multicolumn{2}{c|}{ Above 60 } \\
\cline { 2 - 12 } & Mean & SD & Mean & SD & Mean & SD & Mean & SD & Mean & SD \\
\hline T6 & 6.78 & 1.12 & 7.68 & 2.44 & 7.49 & 2.00 & 7.73 & 1.96 & 7.01 & 1.37 \\
\hline T7 & 10.95 & 1.44 & 10.44 & 1.45 & 10.34 & 1.37 & 10.61 & 1.17 & 11.01 & 1.33 \\
\hline T8 & 8.25 & 1.49 & 9.12 & 2.15 & 8.21 & 1.80 & 8.44 & 1.69 & 8.31 & 0.95 \\
\hline T9 & 4.56 & 1.71 & 5.32 & 2.28 & 5.29 & 2.20 & 4.77 & 1.60 & 4.76 & 1.24 \\
\hline T10 & 4.95 & 1.20 & 5.51 & 1.37 & 5.37 & 1.46 & 5.14 & 1.37 & 5.05 & 1.33 \\
\hline T11 & 2.74 & 1.15 & 3.03 & 1.65 & 2.86 & 1.45 & 2.83 & 1.44 & 2.93 & 0.97 \\
\hline T12 & 3.43 & 1.11 & 4.18 & 1.48 & 3.88 & 1.53 & 3.77 & 1.32 & 3.66 & 1.09 \\
\hline L1 & 8.59 & 1.60 & 8.88 & 1.39 & 8.70 & 1.46 & 8.45 & 1.38 & 8.88 & 1.12 \\
\hline L2 & 10.66 & 1.35 & 10.18 & 1.90 & 10.03 & 1.54 & 9.73 & 1.43 & 9.88 & 1.08 \\
\hline L3 & 12.06 & 1.21 & 12.27 & 1.74 & 12.23 & 1.38 & 12.68 & 1.26 & 13.11 & 0.76 \\
\hline L4 & 14.83 & 2.13 & 15.36 & 2.46 & 14.84 & 2.19 & 15.72 & 1.82 & 14.23 & 1.87 \\
\hline L5 & 25.70 & 2.81 & 24.96 & 2.29 & 24.98 & 2.42 & 23.63 & 2.24 & 24.32 & 2.95 \\
\hline
\end{tabular}

\section{Discussion}

The technique for pedicle screw instrumentation of the spine has gone through significant progress over the last two decades..Knowledge of morphometric characteristics of pedicle is also important for the surgeon to prevent injuries to the pedicle cortex, meninges, nerve roots, joint facets, viscera or adjacent vascular structures due to misplacement or improper orientation of the screws ${ }^{[12]}$. Extensive work has been reported on the pedicle morphology in adult population, however, less is known about the adolescent pedicle morphology. Our results showed that the transverse diameter, transverse and sagittal angulations, and the length of the pedicles follow similar trends as reported by Zindrick et al. ${ }^{[13]}$ and Senaran et al. ${ }^{[14]}$.

In our study the findings suggested that there was continuous variations in the pedicle dimensions and the changes were characterized by increase of diameters in some age groups and decrease in others, but there was an overall increase in the dimensions as the age groups were followed from the youngest to the oldest.

The maximum pedicle width in L5 was found to be highest in above 60 years $13.96 \mathrm{~mm}$ (almost comparable in $40-50$ years) and lowest in 20-30 years $13.42 \mathrm{~mm}$. TPIW of L1, L2 \& L4 was found higher in older age groups (40-60 years) while for L3 and L5 values were higher in younger age groups (20-30 years). In thoracic region transverse pedicle isthmus width of T6, T7, T10, T11 \& T12 vertebrae was found higher in older age group (50-60 years) while in T8 (20-30 years) \& T9 (3040years) width was higher in younger age group.

The variation in the pedicle dimension could be due to agerelated reduction in bone density and osteoporosis which lead to vertebral deformity and elevation in pedicle dimensions as people aged.

Zindrick MR et al. (1987) ${ }^{[13]}$ found that pedicle dimensions become increasingly smaller in the levels above L3 in small or young individuals. In the upper lumbar spine (T11, T12, L1, and L3) pedicles did not reach similar size until 12 years of age. With maturity pedicle diameter increases and vary in different race and ethnicity. Similar findings were observed by Senaran $\mathrm{H}$ et al. (2002) ${ }^{[14]}$.

Mean score of pedicle length(mm) in T6, T7, T9, \& T11 was found higher in older age groups (50-60 years) while in T8, T10 \& T12 values were found higher in younger age groups (20-30 years). In lumber region pedicle length at L2 and L4 was found higher in older age groups (50-60 years) and lower in younger age groups (20-40 years). Pedicle length at L3 and L5 was slightly higher in younger age groups (20-30 years) as compared to older age groups.

The age-wise mean score of transverse pedicle angle in T6 was found to be higher in 50-60 years $\left(7.73^{\circ}\right)$ and lower in 20-30 years $\left(6.78^{\circ}\right)$. In $\mathrm{T} 7$ the transverse pedicle angle was found to be higher in patients above 60 years $\left(11.01^{\circ}\right)$ and lower in 40-50 years (10.34). In T8 the transverse pedicle angle was found to be higher in $30-40$ years $\left(9.12^{\circ}\right)$ and lower in 40-50 years $\left(8.21^{\circ}\right)$. In $\mathrm{T} 9, \mathrm{~T} 10, \mathrm{~T} 11$ and $\mathrm{T} 12$ the transverse pedicle angle was found to be higher in 30-40 years $\left(5.32,5.51,3.03\right.$ and $\left.4.18^{\circ}\right)$ and lower in $20-30$ years $(4.56$, $4.95,2.74$ and $3.43^{\circ}$ ). Then at L1 the transverse pedicle angle was found to be higher in $30-40$ and above 60 years $\left(8.88^{\circ}\right)$ and lower in 50-60 years $\left(8.45^{\circ}\right)$. In L2 and L5 the transverse pedicle angle was found to be higher in $20-30$ years $\left(10.66^{\circ}\right.$ and $\left.25.70^{\circ}\right)$ and lower in $50-60\left(9.73^{\circ}\right.$ and $\left.23.63^{\circ}\right)$. In L3 the transverse pedicle angle is found to be higher in above 60 years $\left(13.11^{\circ}\right)$ and lower in $20-30$ years $\left(12.06^{\circ}\right)$. At last in L4 the transverse pedicle angle was found to be higher in $50-60$ years $\left(15.72^{\circ}\right)$ and lower in above 60 years $\left(14.23^{\circ}\right)$ respectively. Mughir AM et al. (2010) ${ }^{[15]}$ did study in adolescent (10-17 years) and adult (18-60) lumbar vertebrae of Malaysian population. He found that values of lumbar pedicles increased in adult group gradually from L1 to L4 while it was same for L5 vertebrae.

Studies of age related variations of the vertebral elements have largely been limited to the vertebral body and intervertebral discs (Allbrook 1956; Ericksen1976, 1978a,b; Oda et al. 1988; Amonoo-Kuofi, 1991; Gocmen-Mas et al.2010) ${ }^{[16-22]}$; in those studies, the vertebral elements were analyzed from an anthropological perspective rather than focusing on clinical or surgical applications. The literature contains very few reports about the vertebral pedicle, and those are limited to the lumbar region (Amonoo-Kuofi, 1995; Mughir et al. 2010) ${ }^{[23]}$.

In a study conducted by Morales-Avalos et al. ${ }^{[24]}$ he demonstrated that the growth of the thoracic spine pedicle from younger to older age was not simply linear; rather, increasing age is associated with a diameter increase in some groups and a decrease in others. These differences could be related to physiological and endocrine changes, nutritional factors, the amount and intensity of physical activity performed by individuals at different stages of life, and antidegenerative factors.

\section{Conclusion}

A key to a successful transpedicular screw insertion is that the pedicle is correctly entered by the screw and the walls are not penetrated. Choosing the proper entry point for inserting pedicle screws is the first step to prevent penetration of the pedicle wall. Penetration of the cortex or fracture of the pedicle may result from the use of relatively oversized screws. 
Complications that have been reported due to penetration of pedicle include dural tears, leakage of cerebro-spinal fluid and injuries to the nerve roots with neurological deficits.

This study showed variations in pedicle dimensions among male, females and various age groups of our study population and it was concluded that pedicle dimensions vary among various regions of Indian population itself.

It was also concluded that there are significant differences in the pedicle width of Indian and other ethnic population. In addition, there were significant differences between gender and age groups also. So It is suggested that preoperative CT scans must be done to evaluate morphometry of pedicles and to avoid inadvertent complications. Preparation of the pedicle intraoperative should take into account the orientation of the transverse pedicle angle.

The present study concludes that, the different dimensions of the pedicle which have been studied would be of great help for successful pedicle screw fixation.

There are other variables such as weight and body mass index which may affect the size of the pedicle. This study did not take in to account the aforementioned variables. Therefore, further studies need to be carried out to analyze the effect of weight and body mass index on the pedicle dimensions in the Indian population.

\section{References}

1. Singh R, Srivastva SK, Chittode S. Morphometric measurements of cadaveric thoracic spine in Indian population and its clinical applications. Asian Spine J. 2011; 5(1):20-34.

2. Ghobrial GM, Maulucci CM, Maltenfort $\mathrm{M}$ et al. Operative and nonoperative adverse events in the management of traumatic fractures of the thoracolumbar spine: a systematic review. Neurosurg Focus. 2014; 37:8. 10.3171/2014.4. Focus 1467

3. Aruna N, Rajeshwari T. A Study of Lumbar Pedicle size in South Indians. Anatomica Karnataka. 2011; 5(2):6973.

4. Pal GP, Routal RV. A study of weight transmission through the cervical and upper thoracic regions of the vertebral column in man J Anat. 1986; 148:245-261.

5. Edward C Benzel Spine surgery Technique, complication Avoidance, and management. no. I, 2nd Edition published by Livingstone

6. Li B, Jiang B, Fu Z, Zhang D, Wang T. Accurate determination of isthmus of lumbar pedicle: a morphometric study using reformatted computed tomographic images. Spine (Phila Pa 1976). 2004; 29:2438-2444.

7. Krogman WM, Race differences in human skeleton. In the human skeleton in Forensic Medicine 3rd Edition; Charles C Thomas publishers, USA, 1978.

8. Roy-Camille R, Sailant G, Mazel C. Plating of thoracic, thoracolumbar, and lumbar injuries with pedicle screw plates. Orthop Clin North Am. 1986; 17:147-59.

9. Weinstein JN, Spartt KF, Spengler D, Brick. Spinal pedicle fixation reality and validity of roentgenograms based assessment and surgical factors on successful screw placement. 1908; 13:1392-1416.

10. Steffee AD, Biscup RS, Sitkowski DJ. Segmental spine plates with pedicular screw fixation. Clinical Orthopaedic and related Research. 1986; 203:45-54.

11. Zindrick MR. The role of transpedicular fixation for stabilization of the lumbar spine. Orthopaedics clinics of North America. 1987; 22:333-344.
12. Okutan O, Kaptanoglu E, Solaroglu I, Beskonakli E, Tekdemir I Determination of the length of anteromedial screw trajectory by measuring interforaminal distance in the first sacral vertebra. Spine. 2004; 29:1608-1611

13. Zindrick MR, Wiltse LL, Doornik A. Analysis of the morphometric characteristics of the thoracic and lumbar pedicles. Spine. 1987; 12:160-166

14. Senaran H, Yazici M, Karcaaltincaba M, Alanay A, Acaroglu RE, Mughir AM et al. Morphological comparison between adolescent and adult lumbar pedicles using computerized tomography scanning. Surgical and radiologic anatomy. 2010; 32(6):587-92

15. Allbrook DB. Changes in lumbar vertebral body height with age. Am J Phys Anthropol. 1956; 14:35-39.

16. Ericksen MF. Some aspects of aging in the lumbar spine. Am J Phys Anthropol. 1976; 45:575-580.

17. Ericksen MF. Aging in the lumbar spine II. L1 and L2. Am J Phys Anthropol. 1978a; 48:241-246.

18. Ericksen MF. Aging in the lumbar spine III. L5. Am J Phys Anthropol. 1978b; 48:247-250

19. Oda J, Tanaka H, Tsuzuki N. Intervertebral disc changes with aging human cervical vertebra. Neonate to eighty years. Spine. 1988 13:1205-1211.

20. Amonoo-Kuofi HS. Morphometric changes in the heights and anteroposterior diameters of the lumbar intervertebral discs with age. J Anat. 1991; 175:159-168.

21. Gocmen-Mas N, Karabekir H, Ertekin T, Ediezer M, Canan Y, Izzet- Duyar I. Evaluation of lumbar vertebral body and disc: A stereological morphometric study. Int $\mathbf{J}$ Morphol. 2010; 28:841-847

22. Amonoo-Kuofi HS. Age-Related variations in the horizontal and vertical diameters of the pedicles of the lumbar spine. J Anat. 1995; 186:321-328.

23. Morales- Avalos R, Leyva- Villegas J, Sánchez- Mejorada G, Cárdenas- Serna M, Vílchez- Cavazos F, De León ÁM et al. Age- and gender- related variations in morphometric characteristics of thoracic spine pedicle: A Study of 4,800 Pedicles. Clinical Anatomy. 2014; 27(3):441-50. 